\title{
YOU DIDN'T BUILD THAT. A RELEVANCE-THEORETIC APPROACH TO PRESIDENT OBAMA'S CAMPAIGN FLUB
}

\author{
Samuel Zakowski
}

\begin{abstract}
During the 2012 U.S. Presidential campaign, President Obama turned some heads by stating "If you've got a business - you didn't build that". His opponents argued that this was an attack on private enterprise (with "that" referring to business), while his supporters and fact-checking organizations maintained that "that" referred to what Obama was talking about previously (U.S. infrastructure) and represented his political-economic plan of an increased interlacing of private business with government investment. I argue, from a relevance-theoretic perspective, that both interpretations follow from differing contextual assumptions on the part of the audience. In this sense, the role of contextual assumptions in utterance interpretation is highlighted - different contextual assumptions lead to different cognitive effects if the utterance leaves room for more than one interpretation. Combined with a highly polarized U.S. political arena, where participants pounce on their opponent's every possible miscue, all the ingredients for misunderstanding are present.
\end{abstract}

Keywords: Relevance; Obama; Demonstratives; Accessibility; Misunderstandings.

\section{Introduction ${ }^{1}$}

The 2012 U.S. presidential campaign was punctuated by foot-in-mouth blunders from both candidates. One of them came in July 2012, when President Obama caused consternation among supporters and opponents alike in a speech in Virginia. During his talk, the President was ill-advisedly vague in his defense of the role of government in society (the relevant passage is in italics):

"If you were successful, somebody along the line gave you some help. There was a great teacher somewhere in your life. Somebody helped to create this unbelievable American system that we have that allowed you to thrive. Somebody invested in roads and bridges. If you've got a business-you didn't build that. Somebody else made that happen."

${ }^{1}$ This work was funded by the Fund for Scientific Research (FWO; grant number B/10040/02) and the Special Research Fund (BOF; grant number B/13790/01). Many thanks to the anonymous referee for Pragmatics, whose suggestions improved this paper tremendously. All remaining errors are, of course, my own. 
The right side of the U.S. political spectrum blew a gasket, decrying the President's supposed attack on private enterprise. James Taranto, writing in The Wall Street Journal, argued that "[t] $]$ he president's remark was a direct attack on the principle of individual responsibility, the foundation of American freedom." "2 Jennifer Rubin, a conservative columnist for the liberal Washington Post, attacked President Obama for his "resentment toward the private sector". ${ }^{3}$ Sarah Pompei, a spokesperson for the Romney campaign, accused the President of denigrating small businesses and stated that "government didn't build the small businesses that are the backbone of this country - everyday Americans built them, and they continue to build on America's greatness every day. Today, they're standing up to say, 'We did build this.",4

Liberal commentators and fact-checking organizations pushed back and blamed conservatives for taking the President's remarks out of context. Michael Smerconish, writing for The Huffington Post, argued that "the context of Obama's two sentences was a far cry from an assault on American entrepreneurship. He was arguing that, while he was willing to cut government waste, he would not gut investments that grow the economy or give tax breaks to the likes of himself or Romney." Jonathan Chait, in New York Magazine, attacked the Romney campaign for "seizing on its opponent's mangled syntax to accuse him of believing something he clearly does not believe.", FactCheck.org noted that "it's clear from the context what the president was talking about. He spoke of government - including government-funded education, infrastructure and research - assisting businesses to make what he called "this unbelievable American system that we have."'?

Yet is it clear that the President referred to "infrastructure' with "that" in "You didn't build that"? Opponents of Obama will argue that surely it is not (it refers to 'business'), while his supporters will argue that it obviously is. It is clear what the President himself meant to convey - he was arguing that private business cannot flourish without public investment in infrastructure (in a broad sense). Nevertheless, the way in which he put what he meant to convey leaves a lot of room for interpretation. Pace Jonathan Chait, it is not at all obvious "from the context of Obama's remarks that he was trying to say that rich people did not build roads and other infrastructure, not that they did not build their own business." Indeed, at first blush it would seem 'business' is

${ }^{2}$ Taranto, J. (July 18, 2012), You Didn't Sweat, He Did. From the WSJ website, accessed the 24th of April 2013

(http://online.wsj.com/news/articles/SB10000872396390444873204577535053434972374)

${ }^{3}$ Rubin, J. (July 24, 2012). Obama is losing his message like nodody's business. From the WP website, accessed the 24th of April 2013 (http://www.washingtonpost.com/blogs/right-turn/post/obamais-losing-his-message-like-nobodys-business/2012/07/24/gJQAy1yK6W_blog.html?wprss=rss_rightturn).

4 Taken from Walshe, S. (July 25, 2012), Romney Camp Continues 'You Didn't Build That' Attacks with Swing State Events. From the ABC News website, accessed the 24th of April 2013 (http://abcnews.go.com/blogs/politics/2012/07/romney-camp-continues-you-didnt-build-that-attackswith-swing-state-events/).

5 Smerconish, M. (July 30, 2012), 'You Didn't Build That!' in Context. Accessed the 25th of April 2013

http://www.huffingtonpost.com/michael-smerconish/you-didnt-build-that-in-c_b_1721794.html

${ }^{6}$ Chait, J. (July 20, 2012), How 'You Didn't Build That' Violated Conservative P.C. Accessed the 25th of April 2013 (http://nymag.com/daily/intelligencer/2012/07/how-obama-violated-conservativepc.html).

${ }^{7}$ Kiely, E. (July 23, 2012 [updated July 24]), 'You Didn't Build That,' Uncut and Unedited. Accessed the 25th of April 2013 (http://factcheck.org/2012/07/you-didnt-build-that-uncut-and-unedited/). 
a wholly plausible referent for "that" - intuitively, it seems reasonable that the last possible referent will be the most active in the listener's short-term memory when he or she infers the indexical and, hence, that it will be the prime candidate for reference assignment. As such, there seems to be no reason to assume that the 'business' interpretation would be wrong - as we will see below, language processing is geared towards yielding adequate cognitive rewards for the least amount of cognitive effort possible (Sperber \& Wilson 1993: 7; Carston 2002: 45; Hall 2007: 156; Clark 2013: 7). If an acceptable candidate for reference assignment is available at minimal cognitive cost - as seems to be the case here -, there should be no apparent incentive to reject it. Yet the 'business' interpretation has been denounced by liberal and watchdog organizations alike as unfair.

Why, then, would a hearer override his/her reasonable - if they are indeed reasonable - intuitions about the referent of "that" (i.e., "business") and look towards less manifest referents (i.e., 'infrastructure') - if 'infrastructure' is indeed less manifest? In this paper, I would like to look at the linguistic mechanisms behind the choice of one or the other interpretation, employing the cognitive framework of relevance theory (Sperber \& Wilson 1995², 2005/2012). It will become clear that reference assignment depends not on the context "such as it is', the "actual state of the world" (if such a thing even exists, linguistically speaking), but rather on the degree of accessibility of certain contextual assumptions on the part of the hearer (Sperber \& Wilson 19952: 15). On the relevance-theoretic view, contextual assumptions are key to utterance interpretation, and the speaker would do well to take into account which assumptions are more or less manifest to the hearer if he wants to avoid needless misunderstandings or controversy.

\section{The problem}

First, we need a more fine-grained picture of the nature of the problem - what are the opposing views defended by the different camps, exactly? Only after this has been firmly established can we turn to the mechanisms underlying the divergent interpretations - why do the different camps hold these opposing views?

The problem is a pragmatic one. H.P. Grice, in his seminal Studies in the Way of Words, famously argued for a distinction between what is said and what is implicated (1975/1989: 24). If I say 'I am thirsty', I say that I am experiencing thirst; I can imply any number of things, most likely the fact that I would like a drink (but I could also, for example, be fasting and pointing attention to that very fact by saying I am thirsty). For Grice, 'what is said' can be recovered by decoding the conventional semantic content of the utterance, plus - if necessary - assigning reference to indexicals and disambiguating ambiguous expressions. ${ }^{8}$ 'What is implicated' amounts to what the speaker indirectly communicates and, hence, what the listener has to infer using rational, pragmatic principles (cf. Clark 2013: 48).

This account has been found to be inadequate in relevance theory (and most, if not all, modern pragmatic theories), which assume a far larger gap between what is said and what the speaker means (see e.g. Carston 2002; Recanati 2004; Travis 2008; Sperber \& Wilson 2005/2012). Relevance theory (henceforth RT) distinguishes between what is encoded and what is meant by the speaker. What is encoded, according to RT, does not

\footnotetext{
${ }^{8}$ Grice 1975/1989: 25; cf. also the discussion in Sperber \& Wilson 2005/2012: 8.
} 
amount to what is explicitly communicated - inference plays a crucial role in establishing what the speaker says, i.e. explicitly communicates. As such, pragmatic mechanisms contribute to what the speaker says - contra Grice, who limited the role of inference to the recovery of 'what is implicated'. In this sense, both what the speaker means to say (communicate explicitly) and what he means to imply (communicate implicitly) can only be derived through inference.

Although RT is based on the duality between what is coded and what is meant, then, there are three different steps in the process of utterance interpretation (cf. Clark 2013: 299; also e.g. Wilson \& Sperber 1993, 2005/2012: 12):

(i) Logical form: a linguistic expression which has been developed into a semantic representation - it contains gaps and is not yet fully propositional.

(ii) Explicature: the logical form is the basis for the explicature - it is inferentially enriched into a full proposition. Processes such as (but not restricted to) reference assignment and disambiguation occur when developing a logical form into an explicature.

(iii) Implicature: the explicature combines with the hearer's contextual assumptions to yield an implicature, i.e. a non-explicitly communicated proposition. Like explicatures, implicatures are inferred through pragmatic principles.

These three steps do not occur sequentially - the hearer does not first determine the logical form, then goes on to derive the explicature and finishes by constructing (an) implicature(s) (Wilson \& Sperber 2004: 615). Instead, all three occur in parallel in a process of mutual adjustment - hypotheses about implicatures are shaped by explicatures, but the reverse is true as well (Wilson \& Sperber 2012: 14). The disambiguation of an ambiguous word, for instance, is influenced by the implicatures which follow from the choice for one of the possible word meanings (Carston 2007: 21).

Let us briefly analyze an example (adapted from Recanati 2004: 29):

(A waiter in a restaurant nervously approaches his boss before stating the following)

(1) The ham sandwich has left without paying.

This utterance does not need reference assignment; nor is it ambiguous. Yet it does not make any sense - a ham sandwich cannot leave anything, as it is inanimate. The problem is that the utterance radically underdetermines what the speaker actually means to say. In other words, the logical form which results from semantic decoding does not amount to a full proposition - the logical form can be considered a blueprint for "the occasion-specific pragmatic process of determining the proposition the speaker explicitly communicated" (Carston \& Hall 2012: 55). What the speaker actually wants to convey (i.e., the explicature) is the following (cf. also Recanati 2004: 26):

(2) The ham sandwich orderer has left the restaurant without paying his bill.

As is obvious, the semantic content of (1) has provided the 'skeleton' for the explicature in (2). It is also obvious, however, that (2) is very different from (1). The process which has occurred here is known as free enrichment, which, in this case, mandates the "modulation of a linguistically-encoded concept" (Carston 2007: 24; cf. 
also Recanati 2004: 27) - the inanimate 'ham sandwich' is modulated to the animate 'ham sandwich orderer', and 'paying' is developed into 'paying his bill'. It should be noted that free enrichment is an entirely pragmatic process - it is not linguistically mandated but pragmatically inferred (Carston \& Hall 2012: 57; Recanati 2004: 21). ${ }^{9}$ Only now do we have a fully propositional form which can be judged true or false.

Possible implicatures for (2) are manifold - for example, the speaker could be implicitly asking his boss for permission to go after the ham sandwich orderer; or he could be glorifying in his earlier description of the customer as shifty ("The ham sandwich orderer has left without paying - I told you there was something funny about him', or something to that effect). These implicatures are derived by combining the explicature with contextual assumptions - for instance, the contextual assumption that the boss of a restaurant does not like it when someone leaves without paying, along with the explicature in (2), leads to the possible implicature that the waiter is asking for permission to go after the ham sandwich orderer.

For Grice, as stated above, 'what is said' is simply a matter of combining words with their meaning, assigning reference to indexicals, and determining the exact meaning of potentially ambiguous words. Put more strongly, whereas Grice argued that what is said can be context-dependent (if there are indexicals to be assigned reference; if there are ambiguous words), most modern pragmatic theories contend that what is said is always context-dependent and, hence, the subject of pragmatic inference (Carston 2009: 59). The problem is not (only) that a given utterance is ambiguous or requires reference assignment, but that it radically underdetermines what the speaker actually means to say (Sperber \& Wilson 2005/2012: 23; Carston 2002: 117). Note that, under Grice's model, pragmatic principles only apply to 'what is implicated'. This means that reference assignment and disambiguation provide input for 'what is said' and, as such, are not pragmatically established - as Clark (2013: 164) points out, "Grice seems not to have realized that pragmatic processes were involved in working out "what is said"." Under the relevance-theoretic model, on the other hand, reference assignment and disambiguation fall under the scope of pragmatics, just as free enrichment does they all contribute to the explicature through specific principles of pragmatic inferencing (id.: 65; cf. infra).

In sum, 'what is said', even with reference assignment and disambiguation, cannot fully convey what the speaker means to say. As a consequence, Grice's account leaves a gap between logical form and implicature which relevance theory aims to fill. To do this, we need both context and general cognitive mechanisms to (pragmatically) infer explicatures.

We can now apply the relevance-theoretic architecture to President Obama's remark:

(i) Logical form: "If you've got a business - you didn't build that."

(ii) Explicature: If you own a business - you didn't build [that business] interpretation1 OR [that infrastructure which I have just mentioned $]_{\text {interpretation } 2 \text { with your own hands }}$ or money.

${ }^{9}$ This is not to say that language users will have trouble in understanding (1). Every hearer will immediately understand that the waiter means to say (2) by uttering (1). The process described here is 'subpersonal', i.e. occurs automatically, "in ways that are generally outside our control" (Clark 2013: 104). 
(iii) Implicatures: Many possibilities (of which a large number is dependent on the referent of "that"), including So you should pay a bit more on your taxes or So you should be grateful to the government or So we need to invest more in infrastructure. These possibilities need not exclude each other.

As has become clear, the wires got crossed at the level of the explicature. Whereas some people processed "that" as referring to 'business', others (including the President himself) processed it as pertaining to 'infrastructure' in the broadest sense (education, the "American system", roads, bridges). In what follows, I will concentrate on how it is possible that two feasible explicatures can arise. This discussion will lead to other questions - does one of these interpretations require less processing effort than the other? If not, how can we explain that there are two plausible explicatures? If so, how can we measure processing effort in this case? What are the implications? Who is at fault for the misunderstanding - speaker, audience, or both?

To answer these questions, I now turn to the basic tenets of relevance theory, which will eventually offer a plausible solution to these problems.

\section{Relevance theory: A cognitive approach to language processing}

Relevance theory, as its name suggests, gives pride of place to the concept of relevance in the interpretation of utterances. The notion of relevance is a highly specific one in RT - it is important to clearly articulate this idea before proceeding further in order to understand its implications for a theory of language processing.

The core concepts of RT are organized around so-called ostensive-inferential communication. This type of communication is predicated on being ostensive, i.e. on the speaker's intention to communicate something, on the one hand; and on being inferential, i.e. on the hearer's involvement in making inferences about what the speaker means to communicate, on the other (Clark 2013: 97). If the speaker sends an ostensive stimulus to the hearer, he ${ }^{10}$ assumes (and assumes that his hearer assumes) that it will be worth it for the hearer to dedicate at least some cognitive effort to processing it - if a speaker's stimuli are not worth this effort, a hearer will quickly lose interest in what he has to say (Sperber \& Wilson 2004: 611-2). In other words, "the expectation generated by the ostensiveness of [a communicative, SZ] act is that the communicator has an interpretation of [his] behaviour in mind which [he] thinks you will find significant and that you will not be put to undue effort in arriving at it" (Clark 2013: 99). This is a nontechnical description of the concept of relevance as it is employed within RT, where an utterance is relevant to a hearer if "its processing yields [...] positive cognitive effects" (Sperber \& Wilson 2004: 608) by combining with contextual assumptions (Sperber \& Wilson 2005/2012: 6). There are, then, three aspects to relevance:

(i) Processing: Developing an utterance into an explicature and deriving implicatures requires processing effort. Other things being equal, increased processing effort equates to decreased relevance (Clark 2013: 106).

\footnotetext{
${ }^{10}$ Henceforth, the speaker will be indicated with the masculine pronoun, the hearer with the feminine pronoun. Relevance theorists usually do the opposite and indicate the speaker with the feminine pronoun, but, as the speaker is a concrete person in the form of the President and hence male in this case, use of the masculine pronoun is aimed at preventing confusion.
} 
(ii) Positive cognitive effects: A stimulus can only be relevant if it leads the hearer to certain conclusions, or, as Clark (2013: 31) put it, "adjustments to the way an individual represents the world" (cf. also Sperber \& Wilson 19952: 265). These adjustments are cognitive effects, which can take one of four forms (from Clark 2013: 102; cf. also Sperber \& Wilson 2004: 608): ${ }^{11}$

a. They strengthen an existing assumption on the hearer's part.

b. They lead to the revision of an existing assumption.

c. They contradict and lead to the elimination of an existing assumption.

d. They amount to contextual implications, where new information follows from the combination of new and existing assumptions but would not follow from either alone. A non-linguistic example: The hearer knows that Andy always takes the bus if it rains (existing assumption); the hearer notices that it is raining (new assumption); she now assumes that Andy will be taking the bus today (contextual implication).

(iii) Contextual assumptions: Every person has a unique cognitive environment, which is a cover term for all the contextual assumptions which are manifest to him. The goal of the speaker is to make one or more contextual assumptions manifest or more manifest to the hearer, as sketched in (ii) - in other words, the speaker's goal is to alter the hearer's cognitive environment (Clark 2013: 116). At the time of the speaker's utterance, only a subset of the hearer's cognitive environment will be manifest - if we are talking about basketball, our contextual assumptions about cooking will most likely not be manifest. ${ }^{12}$ For example, if you say 'Robert broke his finger last night' (based on Yus 1999: 494), this will make manifest a part of my cognitive environment to me, including the contextual assumptions that 'Robert' is the name of a player on a football team I am a part of; that that football team had a game last night; that Robert was playing in that football team last night while I was not; that you, the speaker, are also part of that football team; that Robert had broken his ankle just a few months earlier; that I broke a finger when I was five years old; and so on. These contextual assumptions combine with the logical form to produce cognitive effects in one or more of the forms outlined in (ii).

The interaction of these three aspects of relevance leads to an increase or decrease in the relevance of any given stimulus - if processing effort is decreased, relevance is increased; more positive cognitive effects correspond to an increase in relevance as well. Moreover, accessing contextual assumptions requires processing effort as well utterances which necessitate accessing many or non-manifest contextual assumptions are less relevant than those which are based on a limited amount of manifest contextual assumptions. $^{13}$

${ }^{11}$ The addition of 'positive' to 'cognitive effects' was induced by the observation that truth and relevance do not always overlap - false assumptions can lead to "true conclusions" (Clark 2013: 103). Since it would not further our discussion of the President's remark, I will not get into the implications of what this adjustment means for language processing in general.

${ }^{12}$ Of course, they can be made mutually manifest by an interlocutor at any given time if he/she feels that the conversation requires it.

${ }^{13}$ This last caveat was pointed out to me by two reviewers for the Journal of Pragmatics, who commented on an earlier draft of this paper. 
This does not mean that a hearer should keep looking indefinitely for positive cognitive effects when processing a given stimulus. She should stop looking for positive cognitive effects when her expectations of relevance have been achieved - under optimal circumstances, when she has derived the least effort-intensive interpretation which yields positive cognitive effects. This leads us to the relevance-theoretic comprehension heuristic, a "practical procedure" for "constructing a hypothesis" about what the speaker is communicating (from Sperber \& Wilson 2004: 613):

(i) Follow a path of least effort in computing cognitive effects: Test interpretive hypotheses (disambiguations, reference resolutions, implicatures, etc.) in order of accessibility.

(ii) Stop when your expectations of relevance are satisfied (or abandoned).

Other things being equal, maximal relevance (for the hearer) is thus achieved on the most accessible interpretation if it produces positive cognitive effects and, hence, meets the hearer's expectations of relevance (Clark 2013: 36). As such, the hearer assumes that the speaker formulates his utterance so that the first interpretation can reasonably be considered the most relevant one - put differently, she assumes that the speaker will be as relevant as possible given his abilities and preferences, and, consequently, that he will put her to the least amount of processing effort possible (Sperber \& Wilson 2004: 613-4). The speaker, then, needs to be aware not only of the contextual assumptions his audience can bring to the table (cf. supra), but also how his utterance will be processed given that his audience follows the path of least processing effort.

Linking $\S 2$ to the discussion in this section leads to the conclusion that the 'specific principles of pragmatic inferencing' which guide reference assignment, disambiguation, free enrichment and the derivation of implicatures (cf. supra), amount to only one principle, namely the subpersonal, non-demonstrative search for relevance - as Sperber \& Wilson (2005/2012: 6) put it, "the very act of communicating raises precise and predictable expectations of relevance, which are enough on their own to guide the hearer towards the speaker's meaning." In other words, assigning a referent to "that" in the President's utterance is guided by the relevance-theoretic comprehension heuristic. More generally, it is now clear that both explicatures and implicatures are contextually bound and pragmatically established, guided by the search for relevance.

Applying this framework to an analysis of President Obama's remark, we first have to determine which interpretation of "that" is most plausible from the audience's standpoint. Another way to put this is to ask the question of which interpretation ('infrastructure' or "business") is most accessible for the audience. As we have seen, the relevance-theoretic comprehension heuristic as a whole is predicated on the notion of 'accessibility'. Yet it is far from clear what we should understand by this. As accessibility is a broad-ranging concept with many different aspects, I will focus on the one facet which is applicable to President Obama's remark - the accessibility of demonstratives.

\section{Demonstratives: Accessibility, cognitive status and underspecification}

Remember that there were two possible explicatures for the President's remark "If you've got a business, you didn't build that." One designated "that" as referring to 
'business', the other as referring to 'infrastructure'. The problem, then, lies in how the demonstrative "that" is processed, i.e. which referent is assigned to it and how. In this section, I will look at the cognitive mechanisms behind reference resolution, which is, as we have seen, a subtask of developing an explicature. Although the President obviously meant to refer to 'infrastructure' with "that", the secondary literature on referring expressions offers a plausible explanation for the 'business' interpretation this view, while not strictly relevance-theoretic, is similar enough to be incorporated within the RT framework.

Reference, in the specific, technical sense used here, can probably best be described as follows: "[Y]ou decide to refer to something and try to select an expression whose utterance will enable your audience, under the circumstances, to identify that object" (Bach 1992: 145). In other words, out of all the referring expressions which are available to a speaker, he should choose that one which ensures that the hearer assigns the correct referent to it, i.e. the referent which the speaker intended her to identify (cf. Scott 2013: 49). This, of course, implies that different referring expressions point to different referents. The question then becomes how hearers (and speakers) are able to connect referring expressions and referents, and, more specifically, which referents the speaker intends the hearer to identify by using demonstratives (and, even more in particular, the demonstrative pronoun "that"). It is not enough to say, in Zaki's (2011: 96) words, that demonstratives "signal a procedure to direct one's attention to the intended referent as opposed to the other potential referents" - every referring expression does this in its own distinct way. We need a cognitive benchmark against which we can measure, and with which we can predict, in some way, which referent a given referring expression can be connected to. One of the most oft-cited of these benchmarks has been worked out by Mira Ariel $(1990,2001)$ in her Accessibility Marking Scale (AMS).

The AMS centers around accessibility. According to Ariel, a referring expression "codes a specific (and different) degree of mental accessibility" (2001: 31) - put differently, each referring expression indicates how accessible its referent is in the hearer's mind and, hence, restricts the number of available referents. Distance is the crucial measuring stick for establishing referent accessibility (id.: 33) - an entity which has just been mentioned is highly accessible, which means that the speaker will refer to it by using a referring expression which encodes high accessibility (this is usually a pronoun such as he, she or it) (id.: 29). "That", as a demonstrative pronoun, encodes intermediate accessibility on the AMS. In the case of the President's remark, then, there should be no problem - "that" encodes intermediate accessibility, which means that it cannot refer to 'business' as it has just been mentioned and is thus highly (and not intermediately) accessible. 'Infrastructure', on the other hand, as a cover term for the entities which Obama introduced just before the 'If you've got a business' utterance (education, the "American system", roads, bridges), is intermediately accessible. ${ }^{14}$

The AMS does not offer any clues as to why another interpretation of the President's remark may have arisen. As such, it amounts to a reasonably 'clean' explanation in that it provides an overview of what happens when communication is running smoothly and both speaker and hearer understand each other perfectly. However, real-life communication (and use of referring expressions in particular) is

${ }^{14}$ See Recanati (2004: 30-2) for an entirely analogous view on accessibility. Cf. Chafe (1994: 71-3) for a similar view - he uses the term 'activation cost' instead of 'accessibility'. 
much more messy, and requires a slightly different approach. For this, we have to turn to the Givenness Hierarchy (Gundel 2010; Gundel et al. 1993, 2012).

The Givenness Hierarchy is predicated on the concept of cognitive status. Referring expressions encode "information assumed by the speaker about the cognitive status of the intended referent in the mind of the addressee" (Gundel et al. 2012: 251). ${ }^{15}$ These expressions can be placed on a hierarchical scale (ibid.):

in focus $>$ activated $>$ familiar $>$ uniquely identifiable $>$ referential $>$ type identifiable

$\{$ it $\} \quad\{$ that, this, this $\mathrm{N}\}\{$ that $\mathrm{N}\} \quad\{$ the $\mathrm{N}\} \quad$ indefinite this $\mathrm{N}\} \quad\{a \mathrm{~N}\}$

The leftmost referring expression, it, encodes the conventional meaning that the referent which it identifies is 'in focus' in the addressee's mind. Another example is the carpenter, in which the conventionally means that the hearer will be able to uniquely identify the referent which the speaker is referring to - in other words, the speaker is identifying a specific carpenter which the hearer is already aware of. Each status also entails the status to its right - a referent which is activated is also familiar, uniquely identifiable, and so on; a referent which is uniquely identifiable is also referential and type identifiable; a referent which is type identifiable does not entail another cognitive status. As such, the leftmost referring expression restricts the set of possible referents the most; the rightmost referring expression is least restrictive in that respect (Gundel et al. 1993: 276). Applying the Givenness Hierarchy to the President's utterance, it seems that "that" should be processed as referring to 'infrastructure' (again, used as a cover term) here as well - if the speaker had wanted to refer to the entity in focus ('business'), he should have used it.

Thus far, there do not seem to be any major differences between the AMS and the Givenness Hierarchy. ${ }^{16}$ This changes, however, due to the caveat that a referring expression can map to a cognitive status to its left - as Gundel et al. (2012: 265) put it, "forms that explicitly encode a particular status are underspecified for higher statuses rather than excluding them". As every referent which is in focus is also activated, this means that "the minimum cognitive status requirement" for using a demonstrative pronoun is met (Gundel 2010: 156). Gundel (2010: 151) cites the following example from an article in Science:

(3) A restudy of pareiasaurs reveals that these primitive reptiles are the nearest relatives of turtles.

While it is obvious that 'pareiasaurs' is in focus, it is nevertheless referred to by a demonstrative determiner which is connected to the 'activated' cognitive status. Consequently, processing "that" (encoding 'activated' cognitive status) as referring to "business", which is in focus in the President's remark, has empirical parallels when viewed against this background. In this sense, the Givenness Hierarchy seems to be better equipped to deal with idiosyncracies in the use of referring expressions than, for instance, the AMS.

${ }^{15}$ Both the AMS and the Givenness Hierarchy assume that referring expressions encode a certain conventional meaning. As pointed out to me by a reviewer for the Journal of Pragmatics, "relevance theorists completely reject the idea that any indexical (even 'I') encodes a referent."

${ }^{16}$ The resemblance is only superficial, of course - both have a very specific and complex perspective on indexicals, which I cannot do justice here. 
Another distinguishing feature of the Givenness Hierarchy is that it explicitly separates accessibility from cognitive status. Accessibility, under the Givenness Hierarchy framework, correlates with processing effort, which is not the same as cognitive status - although they often overlap (it is less effort-intensive to access entities which are in focus than entities which familiar), it is certainly not impossible for a speaker to employ a referring expression which is lower on the Givenness Hierarchy than expected if it costs less in terms of processing effort and is thus more accessible (id.:161). Contrast the following examples (from id.: 162):

(4) A dog and a cat were running in the park. \#It was black.

(5) A dog and a cat were running in the park. The dog was black.

Although "it" in (4) is higher on the Givenness Hierarchy, it is infelicitous due to the ambiguity of the resulting utterance - both $a$ dog and $a$ cat are in focus and hence possible referents for "it". "The dog" in (5), even though it is lower on the Givenness Hierarchy, is more accessible, since the hearer does not have to go to the extra effort of selecting one of two possible referents, as she would have to do in (4) (cf. Sperber \& Wilson 2004: 614).

Applying this to the President's remark, he could have precluded any ambiguity by opting to use that infrastructure instead of "that" - 'that' as a demonstrative determiner designates 'familiar' cognitive status on the Givenness Hierarchy, but would have been more accessible and prevented controversy by spelling out what the President meant as clearly as possible. He could also, for instance, have opted for these/those things - both refer to activated entities, but the use of the plural would have rendered the interpretation 'that $=$ business' impossible. ${ }^{17}$

Now that we have provided the theoretical background which can explain how the controversy surrounding the President's utterance could arise, we can turn to a discussion of how misunderstandings occur in general. Combining a relevance-theoretic approach to misunderstandings with the Givenness Hierarchy and its implications, we can draw more fine-grained conclusions about why things went wrong in this case, i.e. why some people processed "that" as referring to "business" and others as referring to 'infrastructure'.

\section{Misunderstandings: A relevance-theoretic approach}

As has become obvious by now, the relevance-theoretic model of utterance comprehension is inferential. The speaker's utterance provides linguistic input to the hearer. Driven by the search for relevance, the hearer is able to develop this blueprint into a representation of the speaker's intended meaning via contextual enrichment (reference assignment, disambiguation, and so on). However, most relevance theorists emphasize that communication does not always run smoothly (e.g. Clark 2013: 9, 154;

${ }^{17}$ There are, of course, other components than accessibility or cognitive status to demonstratives. However, since these are not really relevant to the discussion at hand, they will not be treated here. For instance, there is an abundance of secondary literature on the role of demonstratives in encoding distance (where 'distance' is conceptualized in many different ways). For more on this, cf. e.g. Maes \& De Rooij 2007; Zaki 2011: 83-142; Scott 2013, and references cited there. 
Sperber \& Wilson 19952: 43). On the one hand, speakers can be imprecise or careless in their utterances; on the other, hearers have their own goals, preferences and views which may color their interpretation - in RT terms, hearers' cognitive environments influence their interpretations (cf. Bou-Franch 2002). Under the RT model, it is almost miraculous that understanding occurs so often, given everything that can go wrong in communication.

To that point, the question underlying RT is how, "out of the many possible interpretations that utterances and stretches of discourse may have, all of them compatible with the information linguistically encoded, hearers arrive at one interpretation" (Padilla Cruz 2012: 367). As regards the President's remark and the ensuing controversy, this question can be modified to include diverging interpretations - in other words, how do some hearers arrive at one interpretation, and others at another?

The simple answer, of course, is that hearers arrive at their interpretations in their search for relevance. Relevance was defined as the interplay between processing effort, positive cognitive effects and contextual assumptions. It is this last component which holds the key to unlocking the question posed above - different hearers brought different contextual assumptions to the table when processing the President's utterance, which resulted in different cognitive effects. These hearers can be roughly divided into two groups - one which processed "that" as referring to "business", and one which processed "that" as referring to the cover term 'infrastructure'. It is important to note that the cognitive effects which both groups derive, although different in their respective content, are fundamentally similar in nature, i.e. are both positive cognitive effects even if the cognitive effects of one group may not be positive for the other (and vice versa).

We need, then, a clear picture of which contextual assumptions led to which positive cognitive effects. Of the RT trifecta, this leaves processing effort - does one group need more processing effort to derive positive cognitive effects, or do they both need (more or less) the same amount? There is a simple way to measure this - if one group needs more steps than the other to assign reference to "that", their processing effort is increased relative to that other group.

In the following subsection, the different components will be analyzed. As stated above, and as will become obvious, they interlock in meaningful ways - contextual assumptions influence cognitive effects, while processing effort is an important consideration throughout the process of constructing interpretations.

\subsection{Understanding the two interpretations}

On the RT view, the misunderstanding 'that=business' should be regarded as an 'alternative understanding' - the hearer constructs an interpretation which is different from the one the speaker intended. As Yus (1999: 505) puts it, "a wrong selection of contextual information makes the hearer predict that the speaker wants to communicate an alternative explicature, different from the intended explicature". He adds that "if there is more than one 'candidate referent' to be applied to a certain word, a misunderstanding is likely to occur" (ibid.). Note, again, that nothing in Yus' definition precludes hearers who extract the unintended explicature from deriving positive cognitive effects - indeed, for the listener, the utterance "remains relevant, i.e. worth the 
time and processing effort" (Mirecki 2008: 78). Even if 'that=business' is not the interpretation the President intended, it fits into some individuals' cognitive environment and results in cognitive effects. How does this work?

To understand how the two divergent explicatures could arise, we have to turn to the different cognitive environments of the two groups which were defined above. Of course, we cannot look inside the heads of the people who processed the utterance one way or the other - the search for relevance, after all, is a non-demonstrative process (Furlong 1995: 44; Sperber \& Wilson 2004: 607) - but, based on the correlation between a certain interpretation and (lack of) political ideology, we can infer the most important points.

We will start with the 'that=infrastructure' interpretation, as it leads to fewer problems. Even though the search for relevance is a non-demonstrative process, we can tease out the different steps this group of the President's audience went through by following the relevance-theoretic comprehension heuristic: ${ }^{18}$

(i) President Obama said, "If you've got a business, you didn't build that."

(ii) Hearer assumes that President Obama's utterance will be optimally relevant to her.

(iii) Problem: A referent has to be assigned for "that". 'That' encodes 'activated' cognitive status. It will most likely not refer to the entity in focus ("business"), which leaves the only other active entity, which is the infrastructure of the United States (used here as a cover term).

(iv) Provisional explicature: If you own a business - you didn't build that infrastructure with your own hands or money.

(v) Question: Is this interpretation relevant to the hearer? Is it compatible with her contextual assumptions? Does it produce positive cognitive effects?

Yes, if (a subset of) her contextual assumptions are or are similar to one or more of the following:

- President Obama believes that government plays and should play a bigger role in the U.S. economy than Republicans believe it should.

- President Obama is pro-capitalism and believes in a checked free market.

- President Obama believes that government should provide a safety net for less fortunate citizens.

- President Obama believes that extremely profitable businesses and extremely wealthy individuals should pay more taxes than less wealthy businesses and individuals.

If they are, processing "that" as 'infrastructure' will yield one or more of the following positive cognitive effects (or positive cognitive effects highly similar to these), among others: ${ }^{19}$

- President Obama said that the private sector has benefited from government investment - this is logical as he believes in a relatively big role for government in economic success.

\footnotetext{
${ }^{18}$ Of course, this all happens in a fraction of a second - I tease out the different steps to make my point.

19 The three positive cognitive effects noted here are contextual implications - an existing assumption combines with the explicature to produce cognitive effects.
} 
- President Obama said that the private sector has benefited from government investment - this is logical as he believes in the free market but also in its limits.

- President Obama said that the private sector has benefited from government investment - this is logical as he believes that wealthy corporations and individuals should pay more taxes.

As a result, the hearer's contextual assumptions outlined above are strengthened.

(vi) Explicature is accepted, as it produces positive cognitive effects. Obama's remark is processed as 'If you own a business - you didn't build that infrastructure which I have just mentioned with your own hands or money'.

There are no real difficulties here - 'infrastructure' is predicted to be the most plausible referent for "that" on both the AMS and the Givenness Hierarchy. It combines with this group's contextual assumptions to produce positive cognitive effects.

Thumbing through the list of people who inferred the explicature of "that" to be 'business', it becomes obvious that they are all stringent critics of the President's economic policies. Indeed, at the right end of the political spectrum, Obama has been viewed as a proponent of 'big government' style taxing and spending ever since he took office, seizing earnest Americans' hard-earned money and redistributing it to the undeserving poor. The Republican Party, to the right's mind, is the party of low spending, low taxes, and balanced bugets, representing a society where everybody gets what they deserve. This was the right's basic narrative going into the 2012 campaign, against the background of anemic economic growth for much of the President's first term. Put differently, for politically right-leaning voters and media, the contextual assumptions for interpreting everything the President said were that Obama was a 'class warrior' who was bent on reducing America's greatness by stunting its meritocratic tendencies and creating widespread dependency on government. It does not matter whether this is the correct view or not (if there is such a thing) - we will leave that for the history books. What matters is that this was a deeply-held conviction for many of the right's leading voices and a large chunk of its voting base - more ominously for the President, it seemed to hold appeal for the all-important swing voters as well. ${ }^{20}$

It is in this context that President Obama made his remark. The right, then, not surprisingly, came out with guns blazing at this comment which they felt to be representative of Obama's worldview. What is baffling is that the President played right into the Republicans' narrative with his remark. Conservatives had bludgeoned the President from day one as someone who was anti-business and pro-government, taking money from small businesses and pumping it into public programs, when, in the middle of a dogfight for his re-election, the President decided to help them by providing a soundbite which played right into this narrative - in RT terms, right into the cognitive environment of his opponents. For people who lean right in their political views (or for people who have a problem with the President personally), then, these were the cognitive steps undertaken in processing the President's utterance, following the relevance-theoretic comprehension heuristic:

[steps (i)-(iii) are identical to those undertaken by the other group of the President's audience (cf. supra)]

${ }^{20}$ Cf. Thrush, Glenn (2012) Obama's Last Stand: POLITICO Playbook 2012. New York: Random House Publishing, p. 89 (of 244)/p. 47 (of 125) [e-book], speaking about "Romney's poll-tested attack that Obama was a "European" socialist, with a sinister, un-American aversion to capitalism." 
(iv) Provisional explicature: If you own a business - you didn't build that infrastructure with your own hands or money.

(v) Question: Is this interpretation relevant to the hearer? Is it compatible with the hearer's cognitive environments? Does it produce positive cognitive effects?

No, if (a subset of) her contextual assumptions are or are similar to one or more of the following:

- President Obama is anti-capitalism and pro-government. He does not believe in the free market and/or holds private enterprise in disdain.

- President Obama instead believes in a government-dependent society, where hard-working people are taxed heavily to provide revenue for the government to gain more control over our lives.

- President Obama is secretly a socialist who wants to destroy the United States' economic and social fabric from the inside.

If they are, processing "that" as 'infrastructure' will yield no positive cognitive effects, as the explicature does not fit into the hearer's contextual assumptions.

(vi) 'Infrastructure' rejected as referent for that. 'Business' is also available as referent for "that", due to the underspecification of referring expressions (cf. supra).

Question: Is this interpretation relevant to the hearer? Is it compatible with the hearer's cognitive environments? Does it produce positive cognitive effects?

Yes, if the hearer's contextual assumptions are or are similar to those outlined in (v). If they are, processing "that" as 'business' will yield one or more of the following positive cognitive effects (or positive cognitive effects highly similar to these), among others:

- President Obama said that every private sector success is due entirely to government - this is logical as he does not believe in and/or objects to capitalism but instead believes in and/or only trusts government as the main engine of economic growth.

- President Obama said that every private sector success is due entirely to government - this is logical as it provides government with a reason to deprive hardworking citizens of their resources, which he needs to extend government control over our lives.

- President Obama said that every private sector success is due entirely to government - this is logical as stifling private business is a surefire way to destroy the US' economic and social fabric, which is his goal as a closet socialist.

As a result, the hearer's contextual assumptions in (v) are strengthened.

(vii) Explicature is accepted, as it produces positive cognitive effects. Obama's remark is processed as 'If you own a business - you didn't build that business with your own hands or money'.

In this case, matters are more complicated. The most plausible referent, 'infrastructure', is rejected because the resulting explicature does not harmonize with the audience's contextual assumptions and thus does not yield positive cognitive effects. In this sense, the hearers of this second group can be regarded as having gone through more processing effort than the hearers who processed "that" as referring to 'infrastructure'. However, this extra processing effort is warranted because the utterance would produce no cognitive effects otherwise - the search for relevance continues until 
positive cognitive effects are achieved (or until the search is abandoned, which was clearly not the case here) (cf. Furlong 1995: 70).

Two things stand out from this discussion. The first is that deriving the explicature is a mutual adjustment process, whereby contextual assumptions, explicatures and cognitive effects are constantly recalibrated, abandoned or accepted in light of one another (cf. already Goodman 1986: 303; also Sperber \& Wilson 2005/2012: 14; Carston 2007: 21). Contextual assumptions function as constraints on the derivation of explicatures; if no or negative cognitive effects follow from an explicature, the explicature has to be adjusted. Conversely, all three can line up perfectly in a positive feedback loop, as is the case in both interpretations here - the hearer's contextual assumptions form the basis for an explicature which results in positive cognitive effects which strengthen the audience's existing contextual assumptions.

Secondly, there is also a more challenging question - who is ultimately responsible for this breakdown in communication? Speaker, hearer or both? This issue will be treated in the following subsection.

\subsection{Relevance and joint responsibility}

The goal of communication, for RT, lies in the hearer searching for the interpretation of the utterance which the speaker intended to convey (Furlong 1995: 46). Yet in this case it would seem that only one group of the audience (those who processed "that" as 'infrastructure') followed this axiom. It would seem, then, that the blame for this misunderstanding lies squarely at the feet of those who processed "that" as referring to "business".

Yet this is far from the complete picture. Political discourse takes place in a highly charged communicative environment where everyone is looking to portray his or her opponent(s) as negatively as possible - this is not a typical interaction, where speaker and hearer usually cooperate almost naturally (Grice 1975/1989: 26). As a result, speakers who are running for public office should take enormous care in what they say or don't say - this is the reasoning behind the army of political advisers, consultants and PR representatives who accompany anyone who is trying to get elected (or even has been elected) in the United States and beyond. In this sense, the speaker (in this case, the President) is partly responsible for the miscommunication as well - he should have left no room for the misunderstanding to arise. As outlined above, he could have opted to say that infrastructure or these/those things instead of "that" to avoid any ambiguity about the entity he was referring to. In RT terms, the President did not take (part of) his audience's contextual assumptions into account when uttering the remark under consideration - in particular, those contextual assumptions which could combine with his utterance to produce cognitive effects different from the ones he intended the utterance to produce. The combination of possible ambiguity and a polarized audience with very different cognitive environments is obviously fertile ground for misunderstandings (cf. Lamb 2005: 235). As such, both speaker and audience are at fault for the misunderstanding - the difference is that the speaker should have known that a part of his audience would be at fault in this case. ${ }^{21}$

${ }^{21}$ Cf. also Yus (1999: 501), who states that every misunderstanding involves joint responsibility between speaker and hearer. 
It is important for every speaker to be aware of his audience's contextual assumptions - more to the point, every speaker has to make assumptions about his audience's contextual assumptions and how they apply these assumptions to their derivation of the message he wants to convey. Obviously, this is not always possible misunderstandings are part and parcel of every conversation. In this case, however, the President should have known better - he lost his footing in a balancing act which was the backbone of his strategy in this campaign. He was walking a tightrope between electorally unhealthy populism and middle-of-the-road appeal to swing voters - the keyword here was 'fairness'. ${ }^{22} \mathrm{He}$ did not want to come across as someone who resented businesspeople for their success, or someone who wanted to take from the job creators and give to the undeserving takers. He wanted to position himself as a champion of the middle class, protecting their interests, jobs and money against the Republicans, who were so indebted to the big corporations and millionaires who wrote their checks and desired nothing more than to pay as little taxes as possible. Yet Obama always fretted that this was a risky ploy. He argued that big businesses should pay more taxes, without appearing to object to private enterprise. The problem was that this could be subtly incorporated in the Republicans' narrative - Obama as a class warrior who opposed what made America great, i.e. the spirit of free enterprise; Obama as representative of the government taking money from hard-working people to give to people who did not deserve it. As such, Republicans left no opportunity unused to fit the President's policies and words into this predetermined narrative - i.e., into their contextual assumptions. ${ }^{23}$ The President, of course, was aware of this strategy, but was unable, at the time of his utterance, to think of another utterance which would have guided all of his audience towards the intended cognitive effects without an undue amount of processing effort. As stated, such an utterance would not have been difficult to devise - "that" could have been replaced by that infrastructure or these/those things without significantly increasing processing effort.

The upshot is that this misunderstanding involves joint responsibility - the speaker for not taking all of his audience's contextual assumptions into account when he crafted his utterance; the audience for not taking the speaker's goals, views and preferences into account and for being guided, instead, by their own goals, views and preferences in the derivation of the explicature.

\section{Conclusions}

In this paper, I have tried to shed some light on the different interpretations of a remark made by President Obama on the campaign trail in 2012. Obama, talking about the relationship between private business and government investment, stated "If you've got a business - you didn't build that." In assigning reference to "that", the political right interpreted it as referring to 'business' - for them, it was just another piece of evidence to prove that the President has an un-American distaste of free enterprise. For more leftleaning and fact-checking organizations, it was obvious that "that" referred to what

\footnotetext{
${ }^{22}$ Cf. Thrush, Glenn (2012) Obama's Last Stand: POLITICO Playbook 2012. New York: Random House Publishing, p. 87 (of 244)/p. 46 (of 125) [e-book.]

${ }^{23}$ This is not to say that Democrats did not do exactly the same to Mitt Romney's proposed policies and speeches - they did. For the matter at hand, though, only the Republicans' reaction is relevant.
} 
Obama had been talking about previously - the U.S. education system and its infrastructure. For this group, the comment was symbolic of Obama's social liberalism, combining free-market capitalism with government investment and safety valves.

I argued that the problem of the differing interpretations could best be described in terms of relevance theory, which states that the search for relevance, spelled out most clearly in the relevance-theoretic comprehension heuristic, is the guiding principle in processing linguistic utterances. On this view, hearers select the first interpretation which corresponds to their expectations of relevance - in other words, cognitive processing effort is minimized. Conversely, speakers should be aware of this and should ideally leave room for only one possible interpretation of their utterances. If they do not, misunderstandings are liable to ensue.

Relevance theory, at its core, revolves around the interaction of processing effort, positive cognitive effects and contextual assumptions. Positive cognitive effects can only be achieved by combining utterances with contextual assumptions, and accessing contextual assumptions requires processing effort. The heart of the misunderstanding under consideration here lies in the fact that the speaker did not take all of his audience's contextual assumptions into account - in a highly charged political context, a speaker cannot assume that every member of that audience has access to the same contextual assumptions as him and/or is benevolent towards him. In this case, the President did not take his opponents' contextual assumptions into account, which resulted in them processing unintended cognitive effects and, hence, in controversy. On the other hand, the part of the audience which processed "business" as the referent to "that" is responsible for the misunderstanding as well - these hearers disregarded the speaker's intentions in favor of their own preferences and goals.

I would argue that this misunderstanding should not be regarded as an isolated incident. Politics, especially U.S. politics, is a high-octane and extremely polarized affair in which press and opponents alike pounce on every shred of ambiguity they can find. I hope to have shown that relevance theory can provide a comprehensive background to more theoretically adequate discussions of what exactly happens when interlocutors communicate in such a partisan communicative arena.

\section{References}

Ariel, Mira (1990) Accessing Noun-Phrase Antecedents. Bristol: Routledge.

Ariel, Mira (2001) Accessibility theory: An overview. In T. Sanders, J. Schliperoord, and W. Spooren (eds.), Text Representation: Linguistic and Psycholinguistic Aspects. Amsterdam/Philadelphia: John Benjamins Publishing Company, pp. 29-87.

Bach, Kent (1992) Intentions and demonstrations. Analysis 52: 40-146.

Bou-Franch, Patricia (2002) Misunderstandings and unofficial knowledge in institutional discourse. In D. Walton, and D. Scheu (eds.), Culture and Power: Ac(unofficially) knowledging Cultural Studies in Spain. Bern: Peter Lang, pp. 323-341.

Carston, Robyn (2002) Thoughts and Utterances: The Pragmatics of Explicit Communication. Oxford: Blackwell. 
Carston, Robyn (2007) How many pragmatic systems are there?. In M.-J. Frappoli (ed.), Saying, Meaning, Referring: Essays on the Philosophy of François Recanati. New York: Palgrave Macmillan, pp. 18-48.

Carston, Robyn (2009) The explicit/implicit distinction in pragmatics and the limits of explicit communication. International Review of Pragmatics 1: 35-62.

Carston, R., and Alison Hall (2012) Implicature and explicature. In H.-J. Schmid (ed.), Cognitive Pragmatics. Berlin: Mouton de Gruyter, pp. 47-84.

Chafe, Wallace (1994) Discourse, Consciousness, and Time: The Flow and Displacement of Conscious Experience in Speaking and Writing. Chicago: University of Chicago Press.

Chafe, Wallace (1996) Inferring identifiability and accessibility. In T. Fretheim, and J.K. Gundel (eds.), Reference and Referent Accessibility. Amsterdam/Philadelphia: John Benjamins Publishing Company, pp. 37-46.

Clark, Billy (2013) Relevance theory. Cambridge: Cambridge University Press.

Furlong, Anne (1995) Relevance theory and Literary Interpretation. London: University College London [dissertation].

Goodman, Bradley A. (1986) Reference identification and reference identification failure. Computational Linguistics 12.4: 273-305.

Grice, Herbert Paul (1975) Logic and Conversation. In H.P. Cole, and J.L. Morgan (eds.), Speech Acts [= Syntax and Semantics, vol. 3]. New York: Academic Press, pp. 41-58. Reprinted in Paul H. Grice (1989) Studies in the Way of Words. Cambridge: Harvard University Press, pp. 22-40.

Gundel, Jeanette K. (2010) Reference and accessibility from a Givenness Hierarchy perspective. International Review of Pragmatics 2: 148-168.

Gundel, Jeanette K., Nancy Hedberg, and Ron Zacharski (1993) Cognitive status and the form of referring expressions in discourse. Language 69.2: 274-307.

Gundel, Jeanette K., Nancy Hedberg, and Ron Zacharski (2012) Underspecification of cognitive status in reference production: Some empirical predictions. Topics in Cognitive Science 4: 249-268.

Hall, Alison (2007) Do discourse connectives encode concepts or procedures? Lingua 117: 149-174.

Lamb, Clarice (2005) Misunderstandings - a sociolinguistic view on meaning. Letras de Hoje 40.1: 231241.

Maes, Alfons, and Christ De Rooij (2007) (How) do demonstratives encode distance? In Proceedings of DAARC 2007, Lagos Portugal. Centro de Linguistica da Universidade de Porto, pp. 83-89.

Mirecki, Paweł (2008) Misunderstandings and communication failure in Relevance theory - a problem revisited. In E. Mioduszewska, and A. Piskorska (eds.), Relevance Round Table I, pp. 77-85.

Padilla Cruz, Manuel (2012) Epistemic vigilance, cautious optimism and sophisticated understanding. Research in Language 10.4: 365-386.

Recanati, François (2004). Literal Meaning. Cambridge: Cambridge University Press.

Scott, Kate (2013) This and that: a procedural analysis. Lingua 131: 49-65. 


\section{Samuel Zakowski}

Sperber, Dan, and Deirdre Wilson (1993) Linguistic form and relevance. Lingua 90: 1-25.

Sperber, Dan, and Deirdre Wilson (19952) Relevance: Communication and Cognition. Oxford: Blackwell.

Sperber, Dan, and Deirdre Wilson (2004) Relevance theory. In L.R. Horn, and G. Ward (eds.), The Handbook of Pragmatics. Oxford: Blackwell, pp. 607-632.

Sperber, Dan, and Deirdre Wilson (2005) Pragmatics. In F. Jackson, and M. Smith (eds.), Oxford Handbook of Philosophy of Language. Oxford: Oxford University Press, pp. 468-501. Reprinted in D. Sperber, and D. Wilson (2012), pp. 1-27.

Sperber, Dan, and Deirdre Wilson (2012) Meaning and Relevance. Cambridge: Cambridge University Press.

Travis, Charles (2008) Occasion-Sensitivity: Selected Essays. Oxford: Oxford University Press.

Wilson, Deirdre, and Tomoko Matsui (1998) Recent approaches to bridging: Truth, coherence and relevance. UCL Working Papers in Linguistics 10: 173-200. Reprinted in D. Sperber, and D. Wilson (2012), pp. 187-209.

Yus, Francisco (1999) Misunderstandings and explicit/implicit communication. Pragmatics 9.4: 487-517.

Zaki, Mai (2011) The Semantics and Pragmatics of Demonstratives in English and Arabic. Hendon: Middlesex University [dissertation].

SAMUEL ZAKOWSKI (born 1990) is a doctoral student at Ghent University. He is currently working on an analysis of Ancient Greek discourse markers from a relevance-theoretic perspective.

Address: Blandijnberg 2, 9000 Gent, Belgium. E-mail: Samuel.zakowski@ugent.be 